\section{ФИНАНСОВО-БЮДЖЕТНЫЕ АСПЕКТЫ РЕАЛИЗАЦИИ НАЦИОНАЛЬНЫХ ПРОЕКТОВ В РОССИЙСКОЙ ФЕДЕРАЦИИ}

\section{Аннотация:}

Реализация национальных проектов, сформированных в соответствии с указом президента Российской Федерации № 204 от 7 мая 2018 г., способна оказать существенное позитивное воздействие на социально-экономическое развитие страны и ее регионов. Однако масштабный благоприятный эффект названных проектов связан с выполнением ряда условий. Одним из них выступает финансово-бюджетное обеспечение национальных проектов, точнее полнота, своевременность и адресность ресурсов. В статье рассматриваются финансово-бюджетные механизмы реализации национальных (федеральных) и региональных проектов. Акцентируется внимание на обязательности решения таких проблем, как адекватность и своевременность финансирования, совериенствование используемых при этом финансовых инструментов, сочетание преобладающего финансового участия со стороны федерального центра с усилением факторов ответственности и заинтересованности субъектов $P \Phi$ в полном и эффективном применении ресурсной базы национальных проектов. Указывается на целесообразность расиирения полномочий регчонов в рамках реализации национальных проектов. Подчеркивается необходимость более четкой интеграции проектов и системы их финансирования в действующую практику стратегического планирования, в частности в документы стратегического планирования как федерального уровня, так и регионального.

Ключевые слова:

национальные проекты, финансово-бюджетные инструменты, межбюджетные отношения, субъекты Российской Федерации, стратегическое планирование.

\section{FINANCIAL AND BUDGETARY ASPECTS OF THE IMPLEMENTATION OF NATIONAL PROJECTS IN THE RUSSIAN FEDERATION}

The implemmary:

The implementation of national projects, formed in accordance with the Decree of the President of the Russian Federation No. 204 of May the $7^{\text {th }}, 2018$, can provide a significant positive impact on the socio-economic development of the country and its regions. However, a favourable large-scale effect of these projects is associated with providing a number of conditions. One of them is the financial and budgetary support of national projects, more precisely, the completeness, timeliness and targeting of the resources used for the projects. The article considers financial and budgetary mechanisms used for the implementation of national (federal) and regional projects. Attention is focused on the need to solve such problems as the adequacy and timeliness of funding, improving the financial instruments used in this process, and combining the prevailing financial participation of the Federal centre with increasing responsibility and interest of the entities of the Russian Federation in the full and effective use of the resource base of national projects. The paper argues that it is necessary to expand the powers of the regions in the implementation of national projects. Moreover, the study emphasizes the need for more precise integration of national projects and the system of their financing into the current practice of strategic planning, in particular, in the documents of strategic planning both at the federal and the regional levels.

Проблематика так называемых национальных, или приоритетных, проектов (национального проектирования) остается одним из новых направлений экономических исследований. Зарубежной практики, близкой к российским условиям и создающей возможный для перенятия практический опыт, видится мало [1]. Как мы указывали ранее, отечественный опыт фрормирования и выполнения подобных проектов отмечен как достижениями, так и существенными недостатками, недоработками в отношении экономической, институциональной и правовой базы, особенно с учетом специфики их реализации в различных типах регионов страны [2].

Хотя в целом национальные проекты в России исходно формируются по федеральной инициативе, одна из основных целей этих проектов - существенно ускорить темпы хозяйственного и социального развития российских регионов, в частности устранить дисбалансы общеэкономической и социальной инфраструктуры [3]. По имеющимся оценкам, не менее 50 \% мероприятий, планируемых в рамках национальных проектов, фактически относятся к полномочиям субъектов Федерации или к полномочиям по предметам совместного ведения Федерации и ее субъектов. 
Это предполагает тесное взаимодействие Федерации и ее субъектов не только в финансово-бюджетной сфере, но и по всем другим слагаемым реализации национальных проектов. Очевидно, что решение задач, включенных в подобные проекты, требует привлечения средств из региональных и даже местных бюджетов. Это финансовое «соучастие» в первую очередь связано не с нехваткой средств федерального бюджета, а с необходимостью создать фринансовые механизмы реализации, поддерживающие достаточный уровень инициативы и ответственности со стороны субфедерального звена управления.

Предполагается, что в 2019 г. на реализацию национальных проектов из региональных бюджетов было направлено около 5 \% расходов консолидированных бюджетов субъектов Российской Федерации. Казалось бы, это незначительная дополнительная фринансовая нагрузка на расходную часть субфедеральных бюджетов. Однако нужно иметь в виду, что в настоящее время финансовое положение большинства региональных бюджетов остается сложным. Опережающее возрастание затрат из-за возложенных на регионы расходных обязательств текущего характера, их несоответствие имеющимся доходным источникам привели к несбалансированности региональных бюджетов. В результате может измениться тренд последних 2-3 лет: от сокращения государственного долга субъектов Федерации к его возможному увеличению [4]. В итоге субъектам, в которых реализация национальных проектов привела к ухудшению фринансовой ситуации, может потребоваться дополнительная помощь со стороны федерального центра.

Однако дело не только в элементарном дефиците финансовых ресурсов регионов. Наиболее трудным моментом согласования стратегического и бюджетного планирования на региональном уровне являются планирование (хотя бы на 2-3 года) и, соответственно, фрактическое фрормирование ресурсов для реализации функций (объемов) софинансирования со стороны субъектов Федерации государственных программ, национальных проектов и их участия в федеральной адресной инвестиционной программе.

В данном случае возникают сложности нескольких типов. Прежде всего они касаются проблематичности среднесрочного бюджетного планирования и тем более бюджетного прогнозирования, особенно на региональном уровне. В настоящее время бюджетная практика складывается таким образом, что все обязательства по (со)финансированию (т. е. параметры финансирования, представленные в среднесрочных бюджетных планах и прогнозах), помимо бюджета текущего года, большой обязательственной силы не имеют и могут в последующем радикально пересматриваться в зависимости от наличия ресурсов и динамики потребностей в фринансировании «приоритетно отчетных» мероприятий (например, по повышению заработной платы в бюджетном секторе экономики региона). В такой ситуации достаточность средств на софинансирование национальных проектов на перспективный период приобретает вероятностный характер.

Процедурно софинансирование национальных проектов в регионах осуществляется на основе специальных соглашений. Их центральным моментом является фриксация совокупных объектов фринансирования по каждому проекту и доли софинансирования со стороны субъекта Федерации. Таковая в среднем не должна превышать 5 \% или даже 3 \%. Однако, как показала практика, выдержать эту пропорцию оказалось сложно, поскольку сохраняется такая сложная проблема региональных бюджетов, как постоянно увеличивающиеся общие финансовые обязательства. Регионы получают дотации на основные мероприятия национальных проектов, а вспомогательные издержки должны оплачивать сами. В результате фактическое софинансирование национальных проектов в 2019 г. со стороны регионов в отдельных случаях доходило до 50 \% [5]. Субъектам Федерации приходится постоянно «оттягивать» финансовые ресурсы с других направлений бюджетных расходов, чтобы выходить на запланированные показатели выполнения национальных проектов [6].

Кроме того, сложности для согласования стратегического и бюджетного планирования создает очевидная в настоящее время накладка государственных программ и национальных проектов, которая затрудняет понимание того, что именно и в каких параметрах в соответствующем бюджетном году должен софинансировать субъект Федерации. Формально сейчас национальные проекты интегрированы с государственными программами РФ, а региональная «проекция» этих проектов - региональные проекты - с государственными программами субъектов Федерации. Однако на деле эта задача решена не полностью, особенно на уровне субъектов, где часто формируются свои представления о приоритетных направлениях финансирования регионально значимых объектов инфраструктурного и социального характера.

Во многом подобная интеграция государственных программ и национальных проектов апробированная практика системного решения вопросов хозяйственного и социального развития на местах. Действительно, наша система государственного управления уже прошла, по крайней мере в середине 2000-х гг., через один этап инициирования подобных проектов, а затем их инте- 
грации в систему государственных программ [7]. Однако в связи с этим и у экспертов, и у представителей регионального звена управления закономерно возникает вопрос. Если интеграция государственных программ и национальных проектов - объективная неизбежность, для чего нужны проекты как особый инструмент стратегического планирования и бюджетирования, ведь при необходимости можно ограничиться поправками и дополнениями в систему государственных программ, что периодически делается, независимо от практики реализации проектов [8].

Можно сорормулировать некоторые рекомендации относительно совершенствования взаимодействия стратегического и бюджетного планирования в целях полной и своевременной реализации национальных проектов. Приоритетное значение при этом имеет законодательное закрепление самого института национальных проектов и его роли в системе стратегического планирования на всех уровнях управления. Здесь возможно несколько решений: например, фиксация «разделения труда» между национальными проектами и государственными программами, утверждение роли проектов как составной части программ на начальный период их осуществления и пр.

Далее успех государственных программ и национальных проектов в субъектах Федерации во многом определяется согласованием стратегического и бюджетного планирования. Оно может быть действенным только в том случае, если обеспечивается по крайней мере на среднесрочном горизонте, поскольку непосредственными объектами планирования и софинансирования в рамках программ и проектов выступают в основном инвестиционные объекты (проекты). С учетом этого обстоятельства на федеральном и региональном уровнях желательно «подтянуть» используемый горизонт среднесрочного бюджетного планирования. Предположительно, он должен охватывать весь период действия проектов. При этом необходимо одновременно сфрормировать финансовые механизмы, обеспечивающие максимальную достоверность такого планирования (например, путем создания резервных фондов для софинансирования программ и проектов на региональном уровне).

Следует также уточнить приоритетность расходов бюджетов субъектов Федерации на софинансирование целей национальных проектов (через региональные программы) и прочие расходы. Нужно допустить для субъектов возможность временного невыполнения внепроектных целевых установок в сфере бюджетного фринансирования, идущих от федерального центра, если их реализация требует отвлечения средств от софинансирования национальных проектов (и, возможно, наоборот).

Целесообразно разделять и отдельно планировать межбюджетные трансферты, поступающие в субъекты Федерации для финансирования национальных проектов и на прочие цели (дотации на общее финансовое выравнивание, различные стимулирующие ассигнования и пр.). В рамках этой системы межбюджетных отношений важно предусмотреть дополнительные стимулирующие меры для регионов, стабильно обеспечивающих свою долю финансового участия в реализации проектов. Следует рассмотреть возможности для субъектов использовать для софинансирования ресурсы кредитной системы, а также уточнить допустимость обращения к практике государственно-частного партнерства при выполнении национальных проектов.

Целесообразно четко распределить ответственность за полное, своевременное и эффективное расходование средств, поступающих на реализацию проектов. В настоящее время имеются многочисленные свидетельства того, что финансы в регионы формально поступают, но фактически не используются, в частности из-за отсутствия готовых проектов, сложностей многочисленных согласований, в том числе социальных и иных проектов с муниципалитетами и пр. В связи с этим необходимо пересмотреть практику отчетности в данной сфере: от акцента на выделение и «освоение» средств к конкретному перечню объектов, которые предполагалось создать и которые были реализованы на деле.

Важно определиться с тем, как могут быть интегрированы в процесс согласования стратегического и бюджетного планирования стратегии социально-экономического развития субъектов Федерации. При периоде их действия в 10 и даже 15 лет такое согласование возможно лишь при разбиении на ряд этапов, первый из которых (4-5 лет) должен включать в себя участие региона в реализации национальных проектов и на этой основе служить инструментом координирования стратегического и бюджетного планирования. Более того, именно такие стратегии должны обеспечивать формирование на региональном уровне не только достаточных бюджетных средств, но и всех иных необходимых экономических, институциональных, кадровых предпосылок для успешной реализации национальных проектов [9].

В настоящее время регионы страны ратуют за то, чтобы им были даны определенная свобода выбора форм и направлений выполнения национальных проектов без сокращения федерального финансирования, а также разрешение на перераспределение бюджетных ассигнований между подобными проектами, увеличение объемов ассигнований на реализацию проектов за счет 
уменьшения бюджетных расходов, предусмотренных на иные цели. Сейчас закон установил основания для перераспределения межбюджетных трансфертов, предоставляемых субъектам Федерации для осуществления федеральных проектов, входящих в состав национальных. Данная мера значительно расширяет возможности субъектов и позволяет осуществлять оперативный маневр средствами, выделенными на реализацию национальных проектов. Однако в этом случае не совсем ясно, зачем использовать 12 различных проектов, если можно передавать регионам средства одним «блоком» (субсидией), предусматривая расходование этих дотаций по их усмотрению.

\section{Ссылки:}

1. Бедняков А.С., Миэринь Л.А. Национальные проекты России: проблемы и решения // Известия Санкт-Петербургского государственного экономического университета. 2019. № 4 (118). С. 20-25.

2. Бухвальд Е.М. Национальные проекты в системе стратегического планирования в Российской Федерации // Теория и практика общественного развития. 2019. № 2 (132). С. 50-54. https://doi.org/10.24158/tipor.2019.2.8 ; Иванов О.Б., Бухвальд Е.М. Национальные проекты России: региональное измерение // ЭТАП: экономическая теория, анализ, практика. 2019. № 1. С. 37-53. https://doi.org/10.24411/2071-6435-2019-10067.

3. Орлов П.А. Проблемы и перспективы реализации национальных проектов социально-экономического развития Российской Федерации // Вектор экономики. 2019. № 7 (37). С. 19.

4. Бухвальд Е.М. Указ. соч.

5. Гальчева А. Аналитики предсказали рост долгов регионов в 2020 г. [Электронный ресурс] // PБК. 2020. 14 февр. URL: https://www.rbc.ru/economics/14/02/2020/5e452d389a79473fed9c76e6 (дата обращения: 04.03.2020).

6. Алексей Кудрин обозначил 5 ключевых проблем национальных проектов [Электронный ресурс] : пресс-релиз // Сайт Счетной палаты РФ. 2019. 25 дек. URL: http://audit.gov.ru/news/aleksey-kudrin-oboznachil-5-klyuchevykh-problemnatsionalnykh-proektov (дата обращения: 04.03.2020).

7. Гальчева А. Нацпроекты тяжело ложатся на бюджеты регионов [Электронный ресурс] // PБК. 2020. 14 феeвp. URL: https://www.rbc.ru/newspaper/2020/02/14/5e452d389a79473fed9c76e6 (дата обращения: 04.03.2020).

8. Ретинская В.Н. Приоритетные национальные проекты: продолжение государственных программ или новый инструмент государственного управления // Управление социально-экономическими системами / под ред. И.А. Мурзиной, В.Н. Ретинской. Пенза, 2019. С. 6-11; Харитоненков А.С. Эволюция административно-правового механизма управления национальными проектами и государственными программами // Государственное управление. Электронный вестник. 2011. Вып. 26. С. 11.

9. Омарова Т.Д., Омаров Т.Д. Национальные проекты как инструмент реализации Стратегии социально-экономического развития России (региональный аспект) // Региональная экономика: опыт и проблемы : материалы международной научно-практической конференции. Владимир, 2019. С. 101-110.

Редактор: Тюлюкова Мария Олеговна Переводчик: Кочетова Дарья Андреевна 